\title{
Die Hendrik van Eck Gone Medalje, 1984
}

$\mathrm{Na}$ die toekenning van die tweede Hendrik van Eck Goue Medalje aan dr. Niko Stutterheim deur die S.A. Chemiese Instituut op 4 Junie 1984 het die ontvanger 'n geïnspireerde referaat oor ,Die tegnologiese perspektiewe vir die Suid-Afrikaanse nywerheidsontwikkeling" gelewer en, onder andere, die volgende gedagtes geopper:

(a) Ons roem dikwels oor die groter vordering wat in Suid-Afrika gemaak is as in ander state in Afrika, en as die Kraghuis en die Ekonomiese Wonder van Afrika. Ons wys graag na ons gevorderde onderwys- en navorsingsinrigtings en die ontwikkeling van hawens, spoorweë, lughawens, water- en elektriese kragbronne, landbou en uitgebreide industrialisasie.

(b) Ons spog ook telkens met ons militêre slaankrag en die uitgebreide en vindingryke krygsnywerheid.

(c) Hierdie vordering is egter aan slegs die insig, ondernemingsgees en tegniese vaardigheid van 'n relatief klein getal persone te danke.

(d) Ons is geneig om nie te erken dat daar baie gunstige faktore bestaan het waarvoor ons geen krediet kan neem nie, te wete -

(i) die geografiese posisie ten opsigte van die wêreld se seevaartontwikkelings;

(ii) die unieke minerale rykdom van die land: as dit nie aanvanklik vir die diamante en goud was nie, sou Suid-Afrika na alle waarskynlikheid vandag 'n konglomerasie van onbelangrike Afrikastaatjies gewees het;

(iii) diamante en goud het die kapitaal geskep vir die daaropvolgende dryfvere vir immigrante om die eksplorasie na en eksploitasie van verdere minerale aan te durf.

(e) Ten spyte van ons tipies Westerse weelde moet ons aanvaar dat Suid-Afrika oor 'n dubbelslagtige ekonomie beskik: 'n Eerste Wêreldse wat in 'n Derde Wêreldse ekonomie ingeplant is.

(f) Suid-Afrika vertoon nog steeds sekere kenmerke van ander Afrikalande, te wete 'n gebrek aan geskoolde arbeid, verdeelde politieke en kulturele lojaliteite, lae produktiwiteit, beperkte markte, oorbevolking, wisselvallige klimaatstoestande en werkloosheid.

(g) Wat veral ernstige kommer wek, is die lae vlak van opleiding vir die bevolking as geheel. Ten opsigte van die krities belangrike kategorieë van uitvoerende en hoogs geskoolde mannekrag veral is Suid-Afrika se hulpbronne ooreis.

(h) Die groot probleem is dat, voordat hoogs geoefende leerlinge ontwikkel word, daar hoogs geoefende onderwysers moet wees. Kritiese gebiede bly steeds die Wiskunde en die Wetenskap. Dr. Stutterheim het verskeie voorstelle gemaak oor hoe hierdie opleiding uitgebrei en bespoedig kan word.

(i) Hy het benadruk dat waar staatsamptenare belangrike salarisverhogings ontvang het, daar nog geen sodanige verhogings aan die onderwys toegeken was nie. Hierdie beroep is die belangrikste in enige land en dit behoort 'n nasionale voorkeur te wees om die onderwysberoep aantreklik te maak, veral vir die jongeres.

(j) Dr. Stutterheim het daarna drie gebiede uitgelig waarop Suid-Afrika oor kragte beskik, maar dat dáár tog ook knelpunte bestaan:

(i) Energie

(ii) Materialenywerheid

(iii) Nywerheidsnavorsing en -ontwikkeling.

(k) Steenkoolbronne: Suid-Afrika is goed bedeeld met steenkoolbronne wat ons in staat gestel het om reusekragsentrales en vloeibare brandstofvervaardigingsaanlêe te ontwikkel. Die medium- en laegraadse steenkool sal as gevolg van volgehoue navorsing vir verdere ontwikkeling benut word. Die probleem van watervoorsiening en lugbesoedeling moet in hierdie verband ook ernstige aandag geniet.

Die verbruik van steenkool as energiebron van $80 \%$ van die energiebehoeftes in Suid-Afrika verskil van dié in die res van die wêreld, wat net $25 \%$ van hulle energiebehoeftes met steenkool bevredig.

(l) Kernkrag het ook die plaaslike veld van elektrisiteitsontwikkeling betree en verdere aanlêe op kusgebiede, met seewaterverkoeling, kan in die vooruitsig gestel word.

(m) Hidroëlektriese krag: Verdere ontwikkelings soos die Cahora Bassaskema in die buurlande en verder in Afrikagebiede om $\mathrm{krag}$ aan die R.S.A. te lewer, kan in die vooruitsig gestel word. So 'n geval is die Ingaprojek in die Zaïrerivier, nie ver van Kinshasa nie, met 'n potensiaal van 40000 MW-kapasiteit en met Suid-Afrika as die vernaamste kliënt.

(n) Pretroleumbronne in die kusgebied: Die benutting van seepetroleum om die invoere van ruolie te bestry en om alternatiewe of vervangingsprojekte van verdere olie-uit-steenkoolnywerhede te wees. Die laasgenoemde se oprigtingskoste word op RI0 miljard elk gestel. Soekor se olieeksplorasieprogram sal met ywer voortgesit word.

(o) Nuwe materiale: Alhoewel ons navorsingsinrigtings besondere sukses behaal met die veredeling van laegraadse mineraalertse, moet Suid-Afrika aandag gee daaraan om die verdere verwerking van minerale te vermag. Die ontwikkeling van opgeleide mannekrag is weer eens onvoldoende 
en dit moet dringend aandag geniet.

Dr. Stutterheim het die silikonskyfie as voorbeeld geneem om die bykans fantastiese en onbeperkte moontlikhede van die ontwikkeling van spesiale materiale uit verdere edel en onedele minerale te skep. Navorsing word reeds deur die WNNR en die universiteite onderneem.

(p) Navorsing en ontwikkeling: Dr. Stutterheim het gepleit vir groter fondse vir $\mathrm{N}$ en $\mathrm{O}$ en ook daarvoor dat die staatsbeheerde navorsingsinrigtings en hul rade onder die knellende beheer van die staatsdiens uitgeneem moet word en dat hulle slegs aan die Minister en Parlement verantwoording moet doen.

Persoonlike opmerking: Prof. Schutte het na die aanbieding aan dr. Stutterheim verwys as ,,'n monumentale geleentheid". Dit was dít ongetwyfeld, maar vir my was dit ook 'n tragedie dat slegs ' $n$ sestigtal persone dit aangehoor het. Die Eerste Minister behoort dr. Stutterheim uit te nooi om hierdie referaat in die Parlement te herhaal.

F.W. Quass

\section{Amerikaans/Suid-Afrikaanse navorsingsvaart}

Waar die Agulhasstroom die suidelike oseaan suid van Afrika binnedring, vind daar dinamiese prosesse plaas waardeur die liggings van seestrome en seefronte oor kort tydperke dramaties verander. In die proses word omvangryke stroomringe en werwels geskep wat in alle rigtings afdrywe. Daar is alreeds deur middel van satellietafstandswaarneming aangetoon dat hierdie gebied van die hoogste dinamiese veranderlikheid in die wêreldoseaan vertoon. Om so 'n snel veranderende gebied oseanologies deeglik te ondersoek, stel baie hoë logistiese en tegnologiese eise.

$\mathrm{Na}$ jarelange samesprekings, oorleg en beplanning is die omvangrykste en intensiefste navorsingsvaart wat nog hier uitgevoer is, in November en Desember van 1983 in die suidelike lope van die Agulhasstroom uitgevoer. Hierdie projek is gesteun deur navorsingsgroepe van vyf Amerikaanse navorsingsinstitute, insluitende die Columbia-universiteit en die befaamde Woods Hole Oceanographic Institution, en van sewe

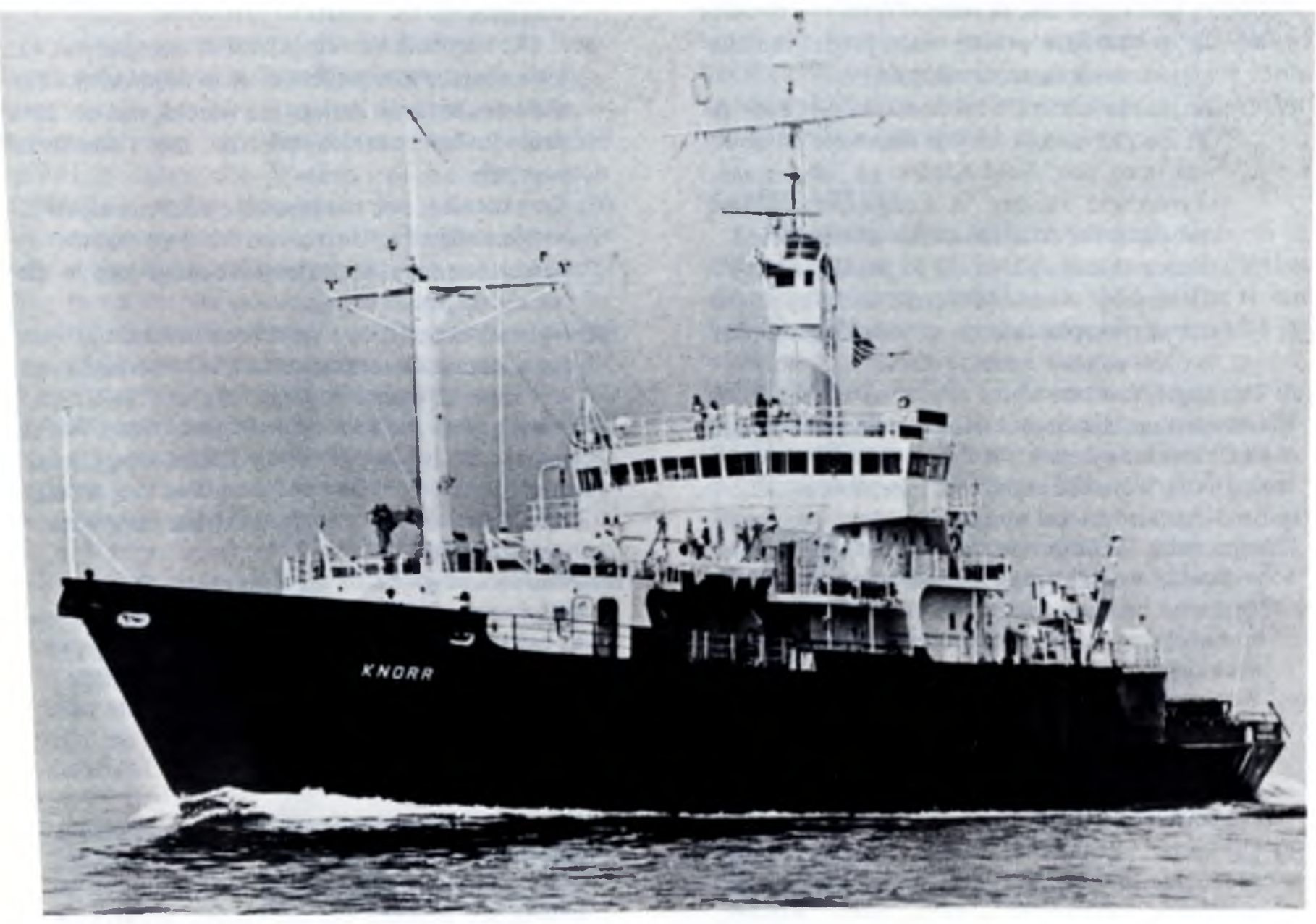

Die navorsingskip Knorr van die Woods Hole Oceanographic Institution wat onlangs deelgeneem het aan 'n omvangryke navorsingsprojek in die suidelike Agulhasstroom. 
Suid-Afrikaanse instansies, waaronder die Universiteit van Kaapstad, die Universiteit van Rhodes, die Navorsingsinstituut vir Seevisserye, die Nasionale Navorsingsinstituut vir Oseanologie van die WNNR en die Instituut vir Maritieme Tegnologie.

Die kern van die projek het bestaan uit 'n navorsingsvaart op die NS Knorr, die grootste navorsingskip in die Amerikaanse navorsingsvloot. Tydens hierdie multidissiplinêre vaart is daar 'n magdom lesings geneem, sommige tot op $5 \mathrm{~km}$-diepte. Lesings het ingesluit soutgehalte, temperatuur, suurstof, voedingsoute, helium en tritium, terwyl voëlverspreiding, chlorofilverspreiding, soöplankton en ander biologiese verskynsels ook bestudeer is. Die vaartplan was buigsaam en kon voortdurend aangepas word by veranderende stroombewegings omdat, vir die eerste keer in die suidelike halfrond, intydse satellietdekking van die see deur die WNNR aan die skip voorsien is. Bykomend hiertoe is daar tydens en voor die vaart ' $n$ groot aantal drywende weerboeie op strategiese plekke in die sirkulasiepatroon geplaas en die bewegings van hierdie boeie is, via ' $n$ satelliet, intyds aan die navorsingskip verskaf om so die voortdurende navorsingsbeplanning te ondersteun.
Bykomend tot die kernvaart is lesings voor en tydens die vaart in dieselfde gebied geneem deur drie ander skepe, te wete die NS Meiring Naudé, S.A. Agulhas en Africana.

Die magdom nuwe kennis wat so ingewin is, word tans verwerk. Die eerste simposium oor die onderwerp is alreeds deur die Suid-Afrikaanse kontigent op Stellenbosch gehou. Daar is aangetoon dat 'n reusewerwel van ongeveer $300 \mathrm{~km}$ in deursnee gereeld suidoos van Kaapstad aangetref word, iets wat voorheen onbekend was. Die mate waarin water uit die Agulhasstroom die Suidoos Atlantiese Oseaan beinvloed is bepaal. Die afknyping van 'n Agulhasring is vir die eerste keer op see waargeneem en die proses is gevolg. Die herabsorbering van ' $n$ stroom is ook vir die eerste keer gedokumenteer. Hierdie resultate sou nie moontlik gewees het sonder die omvangryke meetmetodes wat tydens die navorsingsvaart toegepas is nie.

Die navorsingsprojek het onder die leiding gestaan van professor A.L. Gordon (vir die Amerikaanse span) en dr. J.R.E. Lutjeharms (leier van die SuidAfrikaanse span). 